\title{
REVISED
}

\section{Capture and Concentration of Viral and Bacterial Foodborne Pathogens using}

\section{Apolipoprotein $\mathbf{H}$}

Erin A Almand ${ }^{\mathrm{a} *}$, Rebecca M Goulter ${ }^{\mathrm{b}}$ and Lee-Ann Jaykus ${ }^{\mathrm{ab}}$

${ }^{\mathrm{a}}$ Department of Plant and Microbial Biology, North Carolina State University, Raleigh, NC, 27695, USA

${ }^{\mathrm{b}}$ Department of Food, Bioprocessing and Nutrition Sciences, North Carolina State University, Raleigh, NC, 27695, USA

Email Addresses:

Erin A Almand - eaalmand@ncsu.edu

Rebecca M Goulter - rebecca_goulter@ncsu.edu

Lee-Ann Jaykus - lajaykus@ ncsu.edu

*Corresponding Author

Erin Almand

Phone: +1 (919) 515-3019

Fax: +1 (919) 513-0014 


\begin{abstract}
The need for improved pathogen separation and concentration methods to reduce time-todetection for foodborne pathogens is well recognized. Apolipoprotein $\mathrm{H}(\mathrm{ApoH})$ is an acute phase human plasma protein that has been previously shown to interact with viruses, lipopolysaccharides (LPS) and bacterial proteins. The purpose of this study was to determine if $\mathrm{ApoH}$ was capable of binding and efficiently capturing two representative human norovirus strains (GI.1 and GII.4), a cultivable surrogate, and four bacterial pathogens (Escherichia coli O157:H7, Listeria monocytogenes, Salmonella enterica serovar Enteritidis, and Staphylococcus aureus). Experiments were carried out using an ApoH-conjugated magnetic bead-based capture followed by pathogen detection using nucleic acid amplification. For all three viruses studied, $>10 \%$ capture efficiency $(<1$ $\log _{10}$ loss in RT-qPCR amplifiable units) was observed. The same capture efficiencies were observed for the bacterial pathogens tested, with the exception of E. coli O157:H7 (approximately $1 \%$ capture efficiency, or $2 \log _{10} \operatorname{loss}$ in CFU equivalents). The efficiency of the capture steps did not vary as a consequence of input target concentration or in the presence of an abundance of background microflora. A complementary platebased capture assay showed that $\mathrm{ApoH}$ bound to a variety of human norovirus virus-like particles. ApoH has the potential to be a broadly reactive ligand for separating and concentrating representative foodborne pathogens, both bacteria and viruses.
\end{abstract}

\title{
Keywords
}

ApoH, detection, norovirus, bacteria, concentration 


\section{$1 \quad 1.0$ Introduction}

2 Foodborne pathogens are responsible for approximately 9.4 million illnesses each year in

3 the United States, with an estimated total illness cost of $\$ 14.0$ billion annually (Batz et al,

4 2012; Scharff, 2012). About 58\% (5.5 million) of these illnesses are caused by human

5 norovirus (Scallan et al, 2011). While the bacterial foodborne pathogens are responsible

6 for fewer illnesses (3.6 million each year), they constitute the majority of serious

7 outcomes (Scallan et al, 2011). Nontyphoidal Salmonella spp., the most common

8 bacterial causative agent, is the leading cause of food-related hospitalizations (35\%) and

9 deaths (28\%) (Centers for Disease \& Prevention, 2013), while Listeria monocyotogenes

10 is the third leading cause of foodborne disease deaths (19\%) (Scallan et al, 2011; Gandhi

11 \& Chikindas, 2007). Two other important foodborne pathogens are shiga toxin-producing

12 Escherichia coli (STEC, for which E. coli $\mathrm{O} 157: \mathrm{H7}$ is the most common serovar.), and

13 Staphylococcus aureus, which causes self-limiting food intoxication associated with food

14 handling and subsequent temperature abuse (Rangel et al, 2005; Kadariya et al, 2014).

16 Regulators and industry alike use microbiological testing as one tool to manage these

17 foodborne disease agents. The inability to cultivate human norovirus in vitro means that

18 separation and concentration of low levels of virus particles from food matrices is

19 necessary prior to detection, which is done using molecular amplification methods.

20 Conversely, it is possible to enrich low concentrations of most bacterial pathogens,

21 however enrichment steps are time-consuming, often taking up to two days. Waiting for

22 test results has many implications, both financial (e.g., storage and warehousing, reduced

23 product shelf-life) and public health in nature. In fact, users of testing methods almost 
24 universally recognize that the enrichment and/or concentration process is the single most

25 limiting factor in the development of near real-time methods for foodborne pathogen

26 detection (Dwivedi \& Jaykus, 2011).

28 There is a need to develop methods that either shorten enrichment times, or allow bypass

29 of enrichment steps. Separation and concentration of pathogens from the sample matrix

30 prior to detection is necessary in order to achieve these goals. This so-called "pre-

31 analytical sample processing" is of increasing interest to the detection sector and

32 approaches have been reviewed elsewhere (Stevens \& Jaykus, 2008; Dwivedi and

33 Jaykus, 2011). The most commonly used methods for pathogen separation and

34 concentration are immuno-magnetic separation (antibody-conjugated paramagnetic

35 beads) or affinity magnetic separation (ligand-conjugated paramagnetic beads) (Fluit et

36 al, 1993a; Fluit et al, 1993b; Liebana et al, 2009; Stevens \& Jaykus, 2008). However,

37 depending on the ligand, these methods have their disadvantages, and none is ideal

38 (Dwidedi and Jaykus, 2011). For example, it is very difficult to find broadly reactive

39 ligands for capture of all human norovirus genotypes (and for some bacteria as well);

40 binding affinities can be poor; and cost and/or shelf-life can be problematic. No ligand

41 has binding specificity to a comprehensive and diverse group of foodborne pathogens.

43 Apolipoprotein $\mathrm{H}(\mathrm{ApoH})$, also known as beta2-glycoprotein I, is an acute phase protein

44 found circulating in human plasma (Bouma et al, 1999). ApoH has already been shown to

45 interact directly with a number of different viruses such as hepatitis B, rotavirus and

46 human immunodeficiency virus (Adlhoch et al, 2011; Stefas et al, 1997; Stefas et al, 
47 2001). It also binds with high affinity to LPS on Gram-negative bacteria (Agar et al,

48 2011) and specific proteins on two Gram-positive pathogens, S. aureus (Zhang et al,

49 1999) and Streptococcus pyogenes (Nilsson et al, 2008). The broad range specificity of

50 ApoH may provide a viable alternative to current organism-specific techniques (e.g.,

51 antibody capture) for the concentration and separation of viral and bacterial pathogens

52 from food or environmental samples.

54 The purpose of this study was to determine whether ApoH-conjugated magnetic beads

55 could be used to capture norovirus (representative human genotypes and the Tulane virus,

56 a cultivable surrogate) and select Gram-negative (E. coli O157:H7 and S. enterica serovar

57 Enteritidis) and Gram-positive (L. monocytogenes and S. aureus) bacteria from solution.

58 The efficiency of this concentration and separation technique was also determined.

\section{$60 \quad 2.0$ Materials and Methods}

\subsection{Virus Strains}

62 The genogroup I, genotype 1 (GI.1) Norwalk virus (NV) (courtesy of Dr. Christine Moe,

63 Emory University, Atlanta, GA) and a GII.4 New Orleans outbreak strain (courtesy of

64 Dr. Shermalyn Greene, North Carolina State Laboratory of Public Health, Raleigh, NC)

65 were obtained as stool samples and diluted 10-20\% in phosphate buffered saline (PBS)

66 (MP Biomedicals, Santa Ana, CA). Tulane virus was propagated in the LLC-MK2 cell

67 line as previously described (Farkas et al, 2008) and recovered after three sequential

68 freeze-thaw cycles. All virus stocks were aliquoted and stored at $-80^{\circ} \mathrm{C}$ until used. Serial 
69 dilutions of whole viruses were prepared in PBS or proprietary 1X Binding Buffer (ApoH

70 Technologies, Villaneuve St Georges, France).

\section{$72 \quad 2.2$ Bacterial cultures and plating}

73 Stock cultures of Escherichia coli O157:H7 (ATCC 43895), Listeria monocyotgenes

74 (ATCC 19115), Salmonella enterica serovar. Enteritidis (ME46) and Staphylococcus

75 aureus (ATCC 25235) (all from the American Type Culture Collection, Manassas, VA)

76 were propagated aerobically overnight at $37^{\circ} \mathrm{C}$ in Brain Heart Infusion (BHI) broth

77 (Fisher Scientific, Waltham, MA) before experiments. Plating for enumeration was

78 carried out using the pour plate technique on BHI agar. Plates were grown for $24-48 \mathrm{~h}$ at

$7937^{\circ} \mathrm{C}$ prior to counting colonies.

80

\subsection{Magnetic Bead Binding to Pathogens}

82 Magnetic bead capture of viruses was performed using the ApoH-CaptoVIR kit (ApoH

83 Technologies), whereas bacteria were captured using both the ApoH-CaptoVIR and

84 ApoH-CaptoBAC kits (ApoH Technologies). Serial dilutions of whole virus particles or

85 bacteria were prepared in 1X PBS (Life Technologies, Carlsbad, CA). One hundred

86 microliters of the serially diluted pathogen was added to $900 \mu 1$ of binding buffer prepared

87 as per the manufacturer instructions (ApoH Technologies). Ten microliters of ApoH-

88 coated magnetic beads (ApoH Technologies) were added to each of the pathogen/binding

89 buffer suspensions and incubated with rotation at $4^{\circ} \mathrm{C}$ for $60 \mathrm{~min}$.

90

912.4 Nucleic Acid Extraction 
92 For the virus samples, beads were removed from the suspension using a magnetic rack

93 and were washed twice with PBS-0.05\% Tween (PBS-T) before being resuspended in

$942 \mathrm{ml}$ of easyMAG Lysis Buffer (bioMérieux SA, Marcy l'Etoile, France). Beads were

95 removed from the lysis buffer using a magnetic rack, and the buffer was processed for

96 RNA extraction using the NucliSENS ${ }^{\circledR}$ easyMAG automated system (bioMérieux), with

97 a final resuspension volume of $40 \mu$. To determine input virus concentration, $100 \mu 1$ of

98 serially diluted virus suspension (described in section 2.1 above) was added to $1800 \mu 1$ of

99 easyMAG Lysis Buffer, which was then processed for nucleic acid extraction as above.

100 RNA was stored at $-80^{\circ} \mathrm{C}$ until use.

102 For bacteria samples, beads were removed from suspension using a magnetic rack and the 103 supernatants were reserved for cultural enumeration. The beads were gently washed and

104 resuspended in $200 \mu 1$ of PBS. The PBS-bead mixture was added to $750 \mu 1$ Lysis Solution

105 in a ZR BashingBead Lysis Tube for DNA extraction using the ZR Fungal/Bacterial

106 DNA Miniprep kit (Genesee Scientific, San Diego, CA, USA) as per manufacturer

107 instructions. To determine input CFU for each bacterial concentration, $100 \mu 1$ of each

108 dilution mixed with $100 \mu 1$ of PBS went directly into the Lysis Solution for DNA

109 extraction. The DNA was reconstituted into $40 \mu \mathrm{l}$ of elution buffer and kept at $-20^{\circ} \mathrm{C}$ until

110 use.

111

112 Samples containing both virus and bacteria were run in parallel, with one sample being

113 processed for viral RNA isolation and the other for bacterial DNA isolation. These

114 samples were prepared as above, however the binding buffer was reduced to $800 \mu l$ to 
115 accommodate the increase in input sample volume. Unlike the initial studies looking at

116 bacteria capture alone, input bacteria concentrations for bacteria-virus co-capture

117 remained constant at approximately $10^{6} \mathrm{cfu} / \mathrm{mL}$, while virus dilutions $\left[10^{-1}, 10^{-2}\right.$ and $10^{-3}$,

118 dilutions corresponding to approximately $10^{4}, 10^{3}$ and $10^{2}$ input RT-qPCR amplifiable

119 units (RT-qPCRU), respectively] were evaluated.

\subsection{Detection and Quantification of Viral RNA}

122 Detection of viral RNA was carried out by reverse transcriptase quantitative PCR (RT-

123 qPCR) using the SuperScript ${ }^{\circledR}$ III Platinum ${ }^{\circledR}$ One-Step qRT-PCR kit (Life Technologies)

124 with the primers and probes outlined in Table 1. The amplification temperature profile

125 was as follows: $30 \mathrm{~min}$ at $50^{\circ} \mathrm{C}, 15 \mathrm{~min}$ at $95^{\circ} \mathrm{C} ; 45$ cycles of $15 \mathrm{~s}$ at $95^{\circ} \mathrm{C}, 30 \mathrm{~s}$ at $60^{\circ} \mathrm{C}$.

126 Thermal cycling was done using a Bio-Rad CFX96 Touch Real-Time PCR Detection

127 System (Bio-Rad Laboratories, Inc., Hercules, CA). Standard curves were generated

128 using 10-fold serial dilutions of RNA extracted from stock virus (GI.1 or GII.4), and

129 RNA extracted from serially diluted cell culture lysate containing Tulane virus.

130 Consistent with others (Tung et al, 2013), the cycle threshold (Ct) values were plotted

131 against each respective dilution, and the highest dilution for which three positive signals

132 were obtained from three separate runs was defined as one RT-qPCR unit (RT-qPCRU);

133 this also corresponded to the lower limit of detection of the assay. RT-qPCR was

134 performed on both sample 'input' and sample 'output' (virus captured by ApoH-coated

135 beads). The capture efficiency was determined by using the following equation: [(RT-

136 qPCRU corresponding to virus captured by ApoH-conjugated beads)/(RT-qPCRU

137 corresponding to input virus)] x 100 (Tian et al, 2008). 


\subsection{Detection and Quantification of Bacteria}

140 As has been previously reported for other ligands (Boulanger \& Edelstein, 1995; Cullison

$141 \&$ Jaykus, 2002), inconsistent counts were obtained when performing cultural

142 enumeration on the ApoH bead-bound bacteria (data not shown). Therefore, capture

143 efficiency for the bacterial work was determined based on loss to supernatant (evaluated

144 using cultural methods) and/or by qPCR performed on DNA extracts corresponding to

145 captured bacteria. For the former approach, input bacteria and the non-adherent bacteria

146 in the discarded supernatant after bead capture were plated for enumeration on BHI agar.

147 Percent capture was calculated using the following formula: [(total concentration of input

148 bacteria-concentration of bacteria in supernatant)/(total concentration of input bacteria)] $\mathrm{x}$

149 100] (Stevens \& Jaykus, 2004).

151 Amplification of bacterial DNA was carried out using the primers and probes described

152 in Table 1. The reagents used were the Platinum ${ }^{\circledR}$ Taq DNA Polymerase kit (Life

153 Technologies) supplemented with a dNTP mix (Life Technologies). The amplification

154 temperature profile was as follows: $10 \mathrm{~min}$ at $95^{\circ} \mathrm{C} ; 40$ cycles of $20 \mathrm{~s}$ at $95^{\circ} \mathrm{C}, 30 \mathrm{~s}$ at

$15556^{\circ} \mathrm{C}$ and $1 \mathrm{~min}$ at $72^{\circ} \mathrm{C}$. The same PCR cycling conditions were used for all bacteria

156 (Rodríguez-Lázaro et al, 2004), done using a Bio-Rad CFX96 Touch Real-Time PCR

157 Detection System. Standard curves were generated using 10-fold serial dilutions of DNA

158 extracted from untreated overnight bacterial cultures. The resulting bacterial $\mathrm{Ct}$ values

159 were plotted against the input bacteria based off of serial dilution and plating, and

160 analyzed using linear regression to determine the slope. To approximate the bacterial 
161 counts, the experimental Ct values were converted to CFU equivalents (CFU-E) by

162 application of the standard curves. Bacteria capture efficiency based on qPCR was

163 calculated as follows: [(qPCR-based CFU-E corresponding to bacteria captured by

164 ApoH-conjugated beads)/(CFU-E corresponding to input bacteria] x 100 (Kramer et al, 165 2009).

166

167 2.7 Virus-Like Particles (VLPs)

168 Three GI virus-like particles (VLPs) [GI.1, GI.6, and GI.7], and six GII VLPs [GII.2

169 (Snow Mountain, SMV), GII.4 (Houston, HOV; Grimsby, GRV), GII.6, GII.7, GII.12

170 and GII.17] (courtesy of Dr. Robert Atmar, Baylor College of Medicine, Houston, TX),

171 were used in this study.

172

1732.8 Plate-Based ApoH Capture Assay

174 VLPs described above were diluted in PBS to a final concentration of $3 \mathrm{mg} / \mathrm{ml}$. ApoH-

175 coated microplates (ApoH Technologies, Villaneuve St Georges, France) were incubated

176 with $100 \mu 1$ of VLP suspension per well (four wells per replicate) at $37^{\circ} \mathrm{C}$ for $90 \mathrm{~min}$ as

177 per manufacturer instructions. Negative controls (four wells of PBS containing no VLPs)

178 were included in all replicates. Suspensions were removed from the wells, and then

179 blocked using Superblock (Thermo Fisher) for $2 \mathrm{~h}$ at $4^{\circ} \mathrm{C}$. Wells were thrice washed

180 using $200 \mu 1$ PBS-T. One hundred microliters of primary antibody (Ab3901 for GI,

181 AbNS14 for GII; courtesy of Dr. Robert Atmar, Baylor College of Medicine) was added

182 to each well at a concentration of $3 \mathrm{mg} / \mathrm{ml}$. Samples were incubated at $37^{\circ} \mathrm{C}$ for $60 \mathrm{~min}$,

183 followed by washing three times with $200 \mu 1$ PBS-T. One hundred microliters of 
184 secondary antibody (Ab6789; Abcam, Cambridge, UK) was then added to each well and

185 incubated at $37^{\circ} \mathrm{C}$ for $60 \mathrm{~min}$. Wells were washed again thrice with PBS-T and $100 \mu \mathrm{l}$ of

186 TMB 2-Component Microwell Peroxidase Substrate System (Fisher Scientific, Waltham,

187 MA) was added with incubation at room temperature for $15 \mathrm{~min}$. Absorbance was

188 measured at 450nm using a TECAN Infinite M200 Pro plate reader (TECAN Systems,

189 Inc. San Jose, CA). Values were considered significant if the ratio between the test

190 sample and the negative control was greater than 2.0 (Tian et al, 2006).

192 2.9 Statistical Analysis

193 Three independent replicates were performed for each experiment. Data for all studies

194 were expressed as mean \pm standard deviation of $\log _{10}$ concentration (tube-based capture 195 assays) or sample/negative control ratio (plate-based assay). All statistical comparisons

196 between samples were done in JMP (SAS Institute, Cary, NC) using the Tukey-Kramer

197 honest significant difference test and considered significant if $\mathrm{p}<0.05$.

$199 \quad 3.0$ Results

200 3.1 ApoH Bead-Based Capture of Whole Virus Particles

201 A comparison of the RT-qPCRU corresponding to whole virus particles before and after 202 capture using ApoH-coated beads is presented in Figure 1. In virtually all instances,

203 there was no statistically significant difference between input virus concentration and that

204 recovered using the ApoH beads ( $p>0.05$ ), indicating a high degree of capture efficiency.

205 On a percentage basis, $>23 \%$ of the input virus was captured by the beads; hence, virus

206 loss during capture was always $<1 \log _{10}$ RT-qPCRU. The limit of detection for TV 
207 capture-RT-qPCR occurred at the $10^{-6}$ dilution, or approximately 100 input RT-qPCRU

208 (Figure 1a); for NV, 10 ${ }^{-4}$, or approximately 10 input RT-qPCRU (Figure 1b); and for

209 GII.4, $10^{-4}$, or approximately 10 input RT-qPCRU (Figure 1c).

210

\section{a) Tulane Virus}

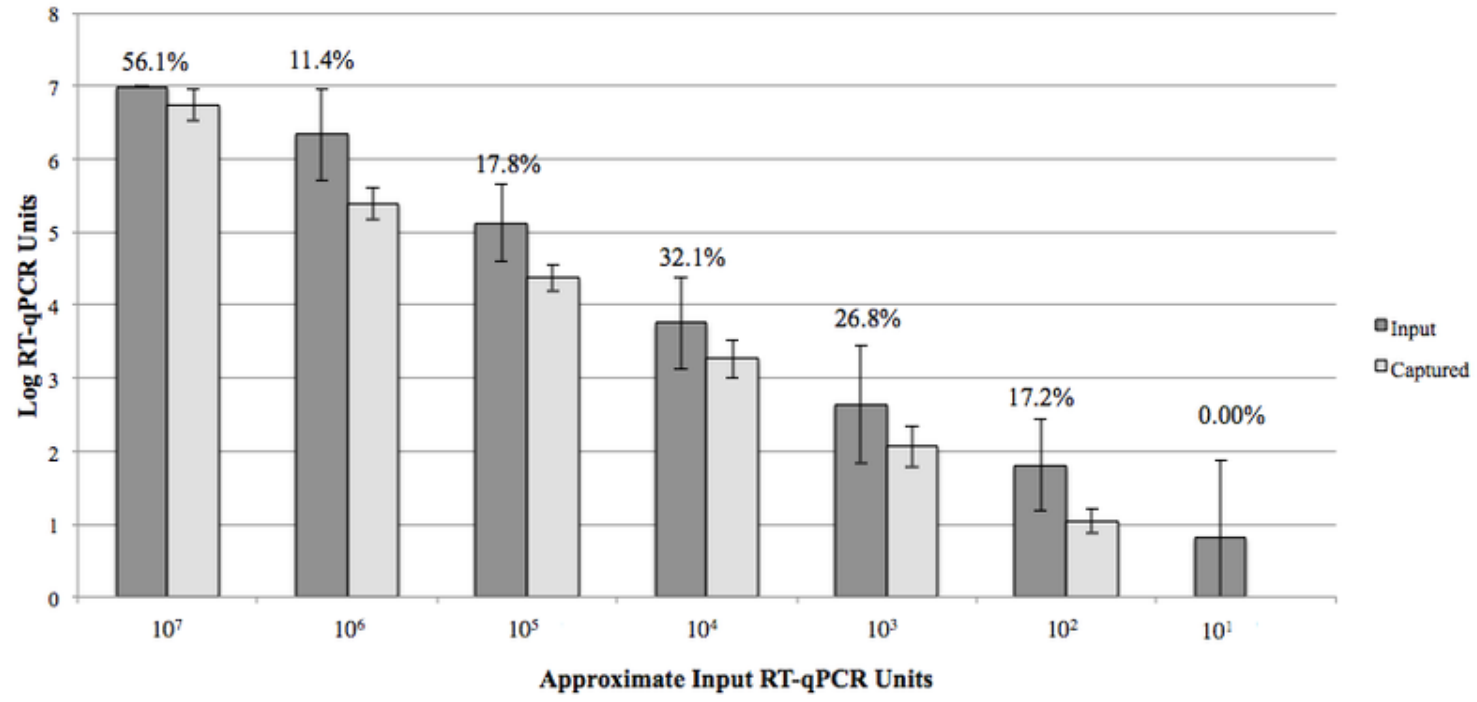

b) GI.1 Norwalk Virus

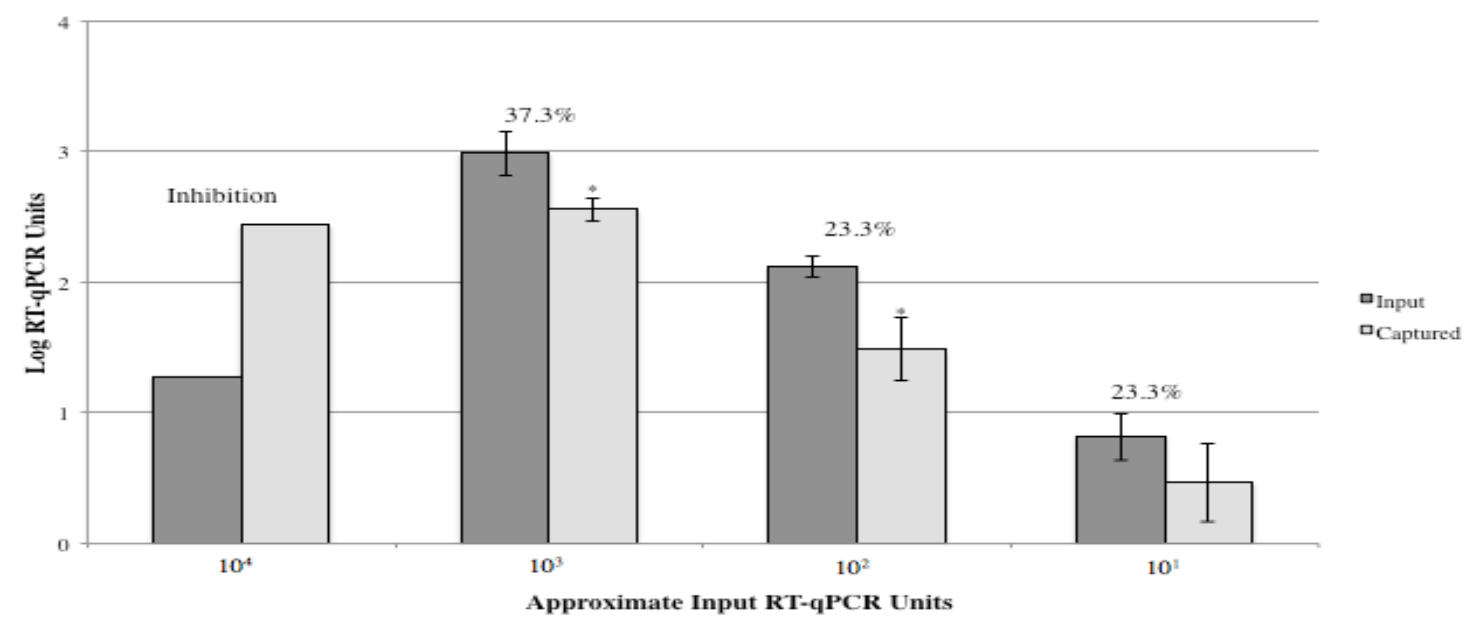




\section{c) GII.4 New Orleans Virus}

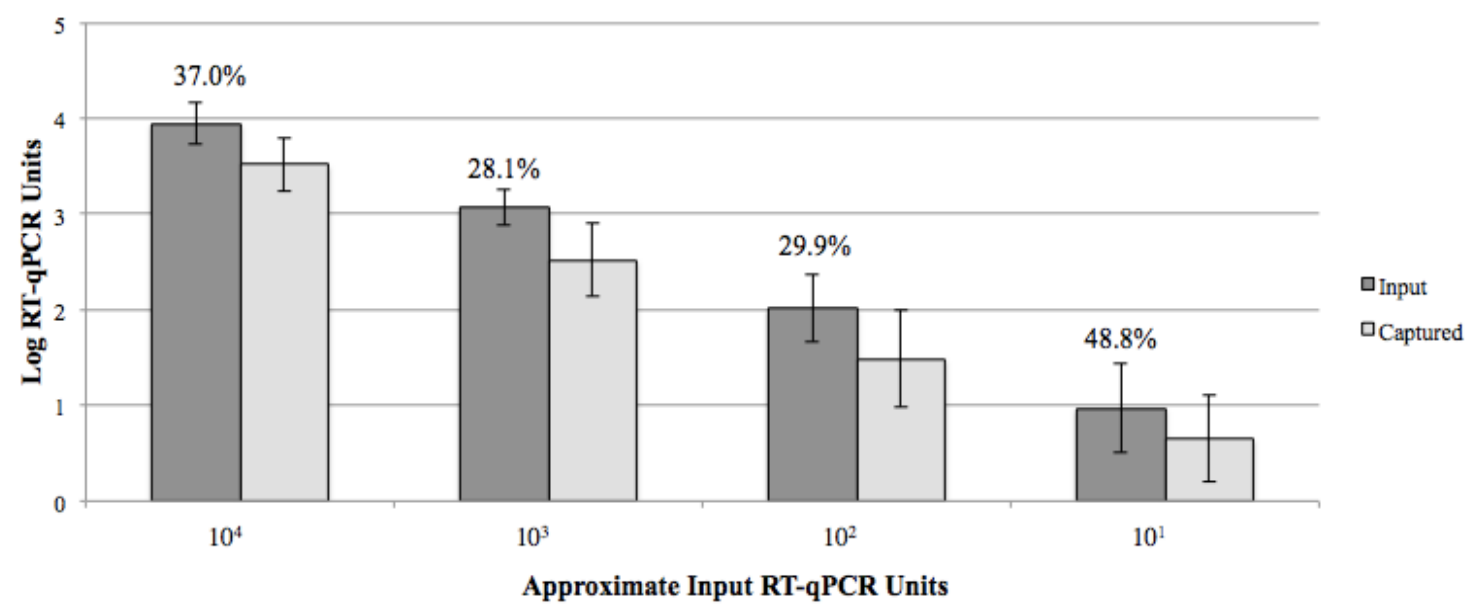

Figure 1. Capture of virus particles using the ApoH-CaptoVIR kit. Serial dilutions of

216 virus stocks were subjected to ApoH capture, magnetic separation, RNA extraction of the

217 virus-bound beads, and detection/enumeration by RT-qPCR. Capture efficiency (\%) was

218 calculated as the ratio of captured virus to input virus as measured in RT-qPCR

219 amplifiable units (RT-qPCRU). There were no statistically significant differences

$220(\mathrm{p}<0.05)$ between input and captured virus at a given input virus concentration. 
222 Because of an interest in evaluating the reactivity of $\mathrm{ApoH}$ with a variety of human

223 norovirus strains, 11 VLP types were used in a plate-based ApoH capture assay. Seven

224 VLP types could be captured by the plate assay (positive/negative ratio >2.0; Figure 1).

225 VLPs GI.6, GI.7, GII.3 and GII.6 showed mean test sample/negative control ratios of

$226<2.0$, meaning poor capture efficiency (Tian et al, 2006). The highest degree of capture

227 was observed for the GII.4 HOV VLP strain, although significant capture and detection

228 was also observed for the GI.1, GII.2 SMV, GII.4 GRV, GII.7, GII.12 and GII.17.

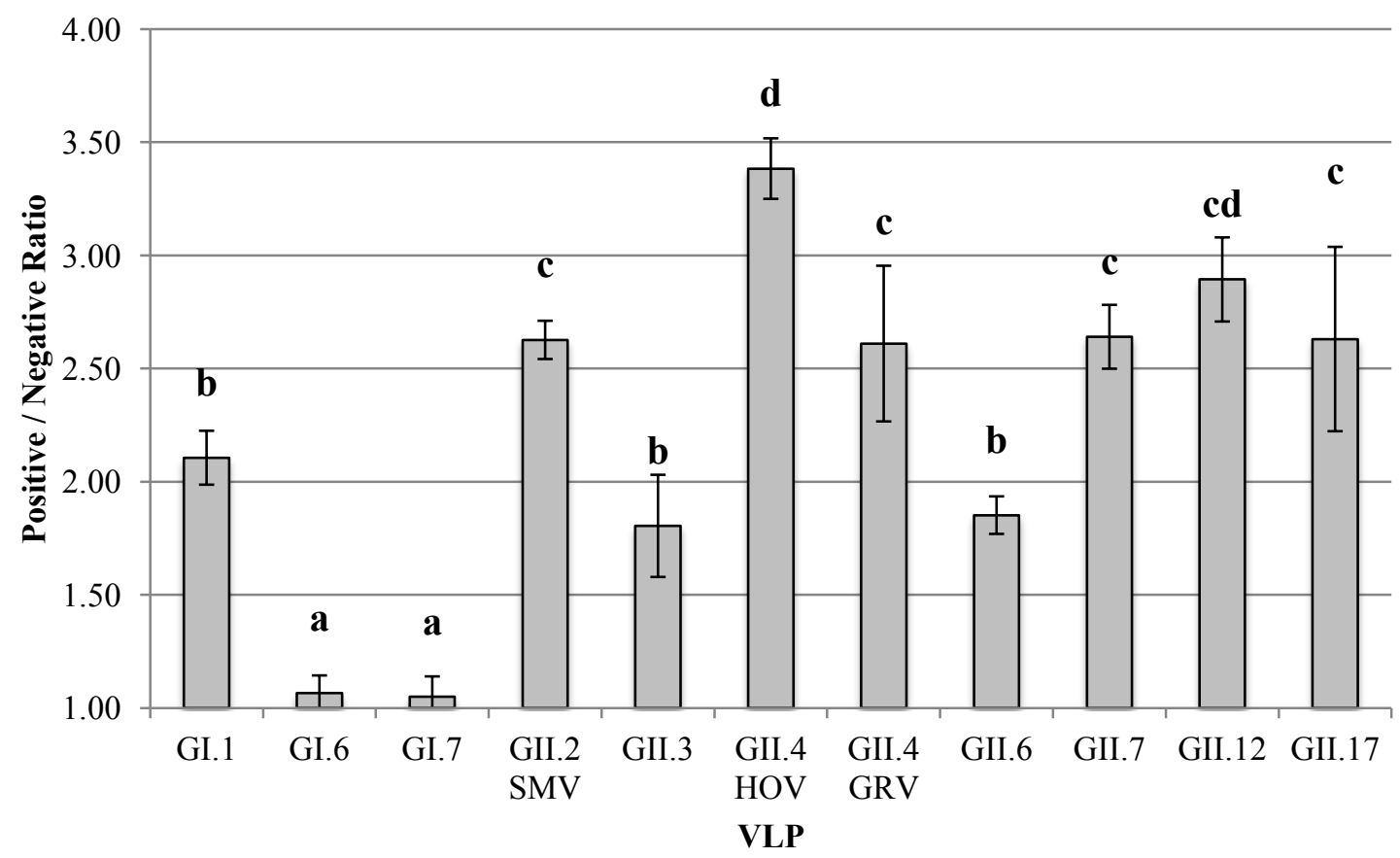

230 Figure 2. Human norovirus VLP binding to ApoH-coated microplates as determined

231 using a capture assay approach. Binding (capture) was considered significant when

232 positive/negative ratios were greater than 2.0 (Tian et al, 2006). Different letters (a, b, c,

233 d) indicate statistically significant differences between binding efficiency when

234 comparing VLP genotypes ( $\mathrm{p}<0.05)$. 
236 The capture efficiency, as evaluated by qPCR and cultural enumeration, for the four

237 bacteria tested using the ApoH-CaptoVIR kit are shown in Figure 3a. Using the qPCR

238 method and E. coli $\mathrm{O} 157: \mathrm{H} 7$, there was a significant difference $(\mathrm{p}<0.05)$ between the

239 input concentration and that captured. Specifically, capture efficiency for E. coli

240 O157:H7 ranged from 2.1-5.0\% for all bacteria concentrations tested, indicating close to

241 a $2 \log _{10} \operatorname{loss}$ during the capture step. For the Gram-positive bacteria and S. enterica, the

242 capture efficiencies were much better, ranging from $29.2 \%$ - 92.0\% (for all initial bacteria

243 concentrations), or $<1 \log _{10}$ loss during the capture step. On the other hand, there were

244 no statistically significant differences ( $p>0.05$ ) when comparing capture efficiencies for

245 all four bacteria based on results using the cultural method (Figure 3b). When

246 comparing the performance of the ApoH-CaptoBAC kit to the ApoH-CaptoVIR kit, a

247 significantly reduced efficiency of capture using both the qPCR and cultural methods was

248 again observed for E. coli $\mathrm{O} 157: \mathrm{H} 7$ (data not shown). The ApoH-CaptoVIR kit was

249 chosen for subsequent experiments due to the desire to evaluate one single kit for its

250 efficacy in capture of both bacteria and viruses. 


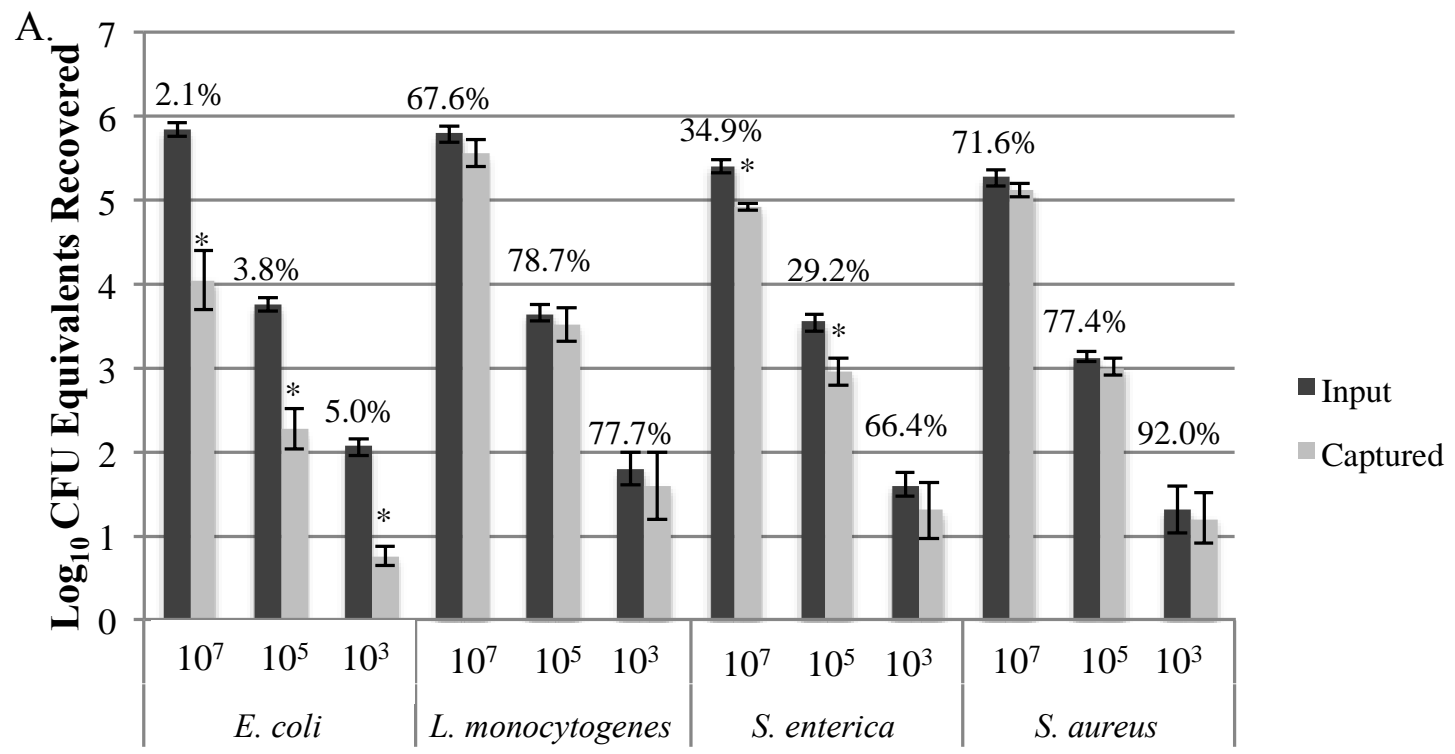

251

Input CFU

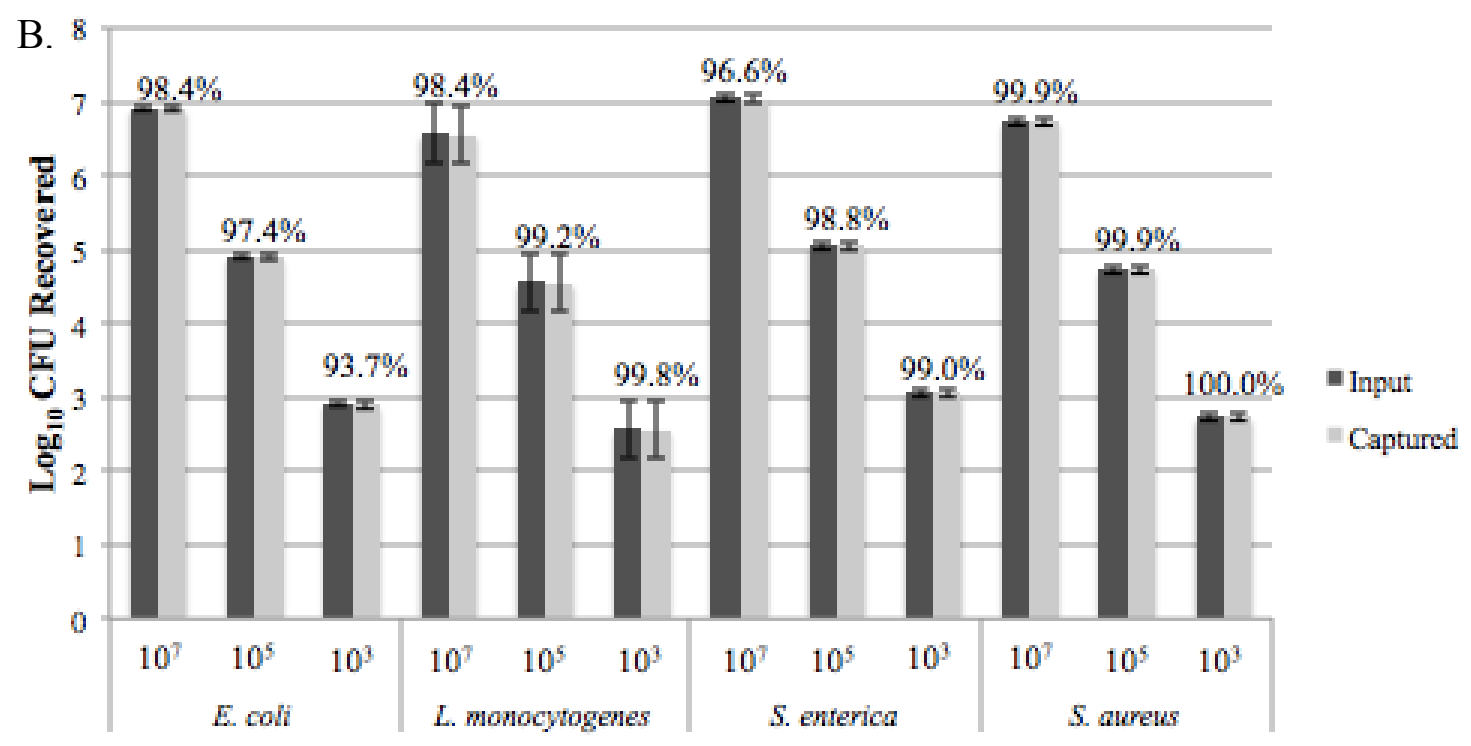

Input CFU

253 Figure 3. Capture of select bacteria using the ApoH-CaptoVIR kit. Serial dilutions of

254 fresh bacterial stocks were subjected to ApoH capture, magnetic separation, DNA

255 extraction of the bacteria-bound beads, and detection/enumeration by RT-qPCR (A); or

256 else by cultural enumeration of the discarded supernatant from the capture step (B).

257 Capture efficiency (\%) was calculated as the ratio of captured bacteria to bacteria virus as 
258 measured in CFU equivalents (A) or as measured by loss to supernatant (B). * Statistically

259 significant difference $(\mathrm{p}<0.05)$ between input and captured bacteria at a given input

260 bacteria concentration. 
262 To evaluate the potential for competition between bacteria and viruses when in the same

263 solution, ApoH capture of GII.4 Sydney human norovirus in the presence of different

264 bacterial pathogens (Figure 4a) and bacterial capture in the presence of virus (Figure 4b),

265 was evaluated. Specifically, input bacteria concentrations for bacteria-virus co-capture

266 experiments remained constant at approximately $10^{6} \mathrm{cfu} / \mathrm{mL}$, while virus input

267 concentration $\left(10^{4}, 10^{3}\right.$ and $10^{2} \mathrm{RT}$-qPCRU) was varied. The virus capture data under

268 these circumstances was consistent with that obtained using virus-only suspensions, with

269 an approximate $1 \log _{10}$ loss in viral genome copy number after capture compared to

270 input, across all bacteria at all concentrations. The bacterial capture performance was also

271 consistent with the previous studies, with a $<1 \log _{10} \operatorname{loss}$ across three out of four

272 bacteria, regardless of viral load. As was the case for bacteria only, the E. coli $\mathrm{O} 157: \mathrm{H} 7$

273 maintained the previously observed 1-2 $\log _{10}$ loss during ApoH capture when suspended

274 in solutions also containing norovirus. There was no effect on either human norovirus or

275 pathogenic bacteria capture efficiency when non-target bacteria and viruses $\left(10^{8} \mathrm{cfu} / \mathrm{ml}\right.$

276 and $10^{12} \mathrm{pfu} / \mathrm{ml}$, respectively) were added to mixed samples prior to ApoH capture. This

277 suggests that ligand saturation did not occur due to the presence of excess background 278 microflora. 


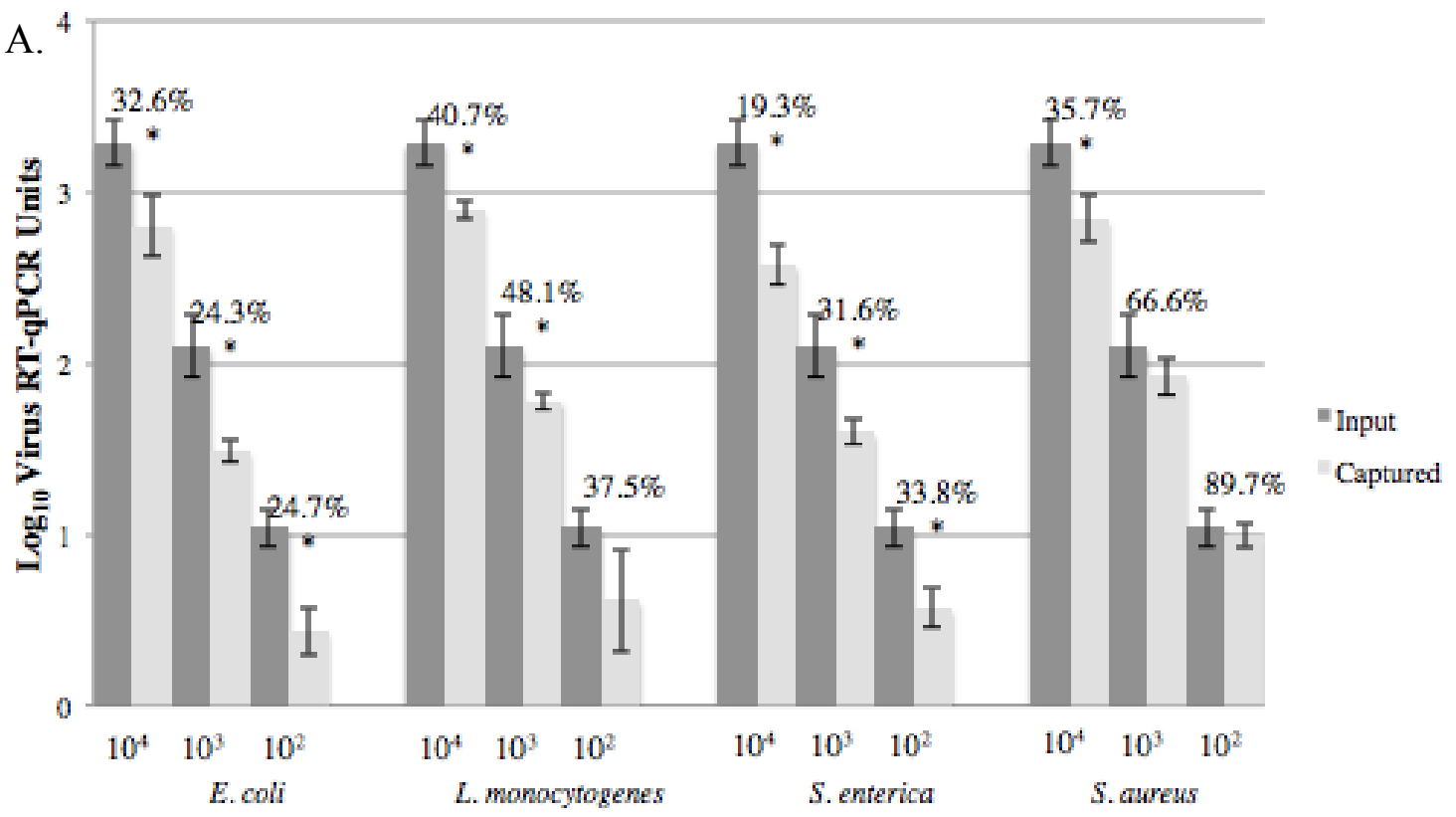

Approximate Input Viral RT-qPCR Units by bacteria

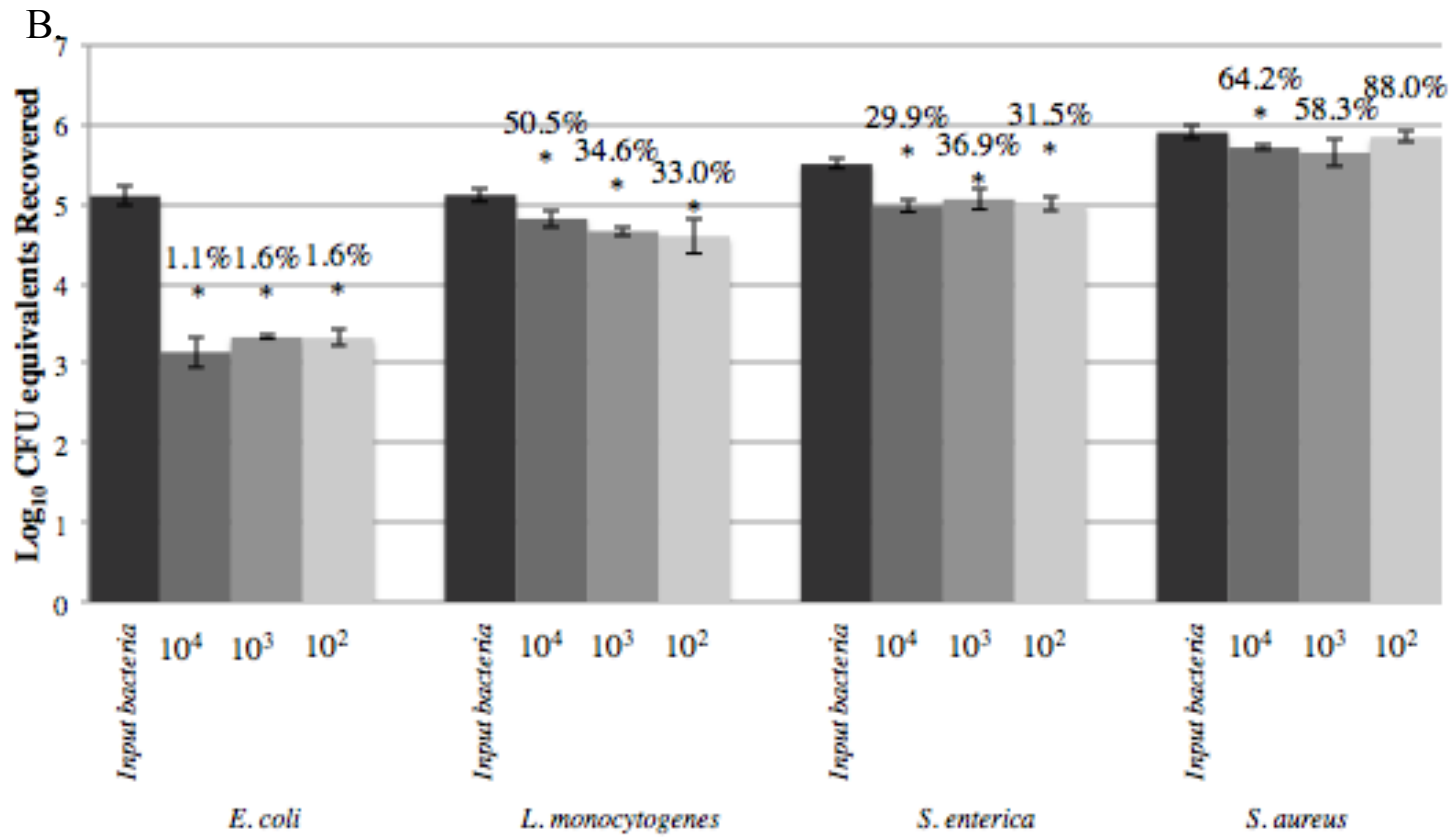

Approximate Input Viral RT-qPCR Units by bacteria

281 Figure 4. ApoH co-capture of whole human norovirus particles and bacterial pathogens.

282 The bacterial pathogens remained at a constant concentration, $10^{6} \mathrm{cfu} / \mathrm{ml}$, while the

283 amount of virus varied, as shown $\left(10^{4}, 10^{3}, 10^{2}\right.$ RT-qPCRU). (A) Virus capture in the

284 presence of the indicated bacterial pathogens, as determined by RT-qPCR. (B) Bacteria 
285 capture in the presence of the indicated virus concentration. Bacterial capture efficiency

286 was based on the qPCR method. *Statistically significant differences between input and

287 captured (A) virus or (B) bacteria.

\section{Discussion}

290 The need to shorten and simplify methods to detect bacterial and viral pathogens in food

291 and environmental samples is well established. The most commonly used approach to

292 achieve this is concentration and purification of the target from the sample matrix just

293 prior to detection. Pathogen concentration methods range from general (e.g. high speed

294 centrifugation, filtration) to specific (immunomagnetic separation), with a emphasis on

295 separating the organisms from sample matrices, removing inhibitors and reducing sample

296 size while maintaining viability/infectivity. Physical and chemical approaches are useful

297 but usually lack specificity. Biological approaches have greater specificity, often using

298 antibodies or phages to target individual bacterial strains, with high capture efficiencies

299 (Dwivedi \& Jaykus, 2011). For example, cell wall-binding domains of bacteriophage

300 endolysins for specific bacteria were conjugated to paramagnetic beads and shown to

301 capture select bacteria with efficiencies of over 90\% (Kretzer et al, 2007). Similar

302 approaches using magnetic beads conjugated to virus cellular recptors and nucleic acid

303 aptamers, to name a few, have been used for capture and detection of human norovirus

304 (Tian et al., 2008; Escudero-Abarca et al., 2014). Unfortunately, concentration strategies

305 such as these are limited in scope, as specialized approaches focus on capturing and

306 detecting a single bacterial or viral pathogen per test. For a more broadly reactive

307 application, a system needs to be developed where strain variation, pathogen type 
308 (bacterial, viral, protozoal) or emerging, as yet unidentified pathogens, may be captured

309 and enumerated.

311 ApoH-bacteria interactions have been documented in the literature, but the protein has

312 not been used before as a capture ligand. For example, anti-ApoH antibodies have been

313 found to be associated with several bacterial infections, and multiple pathogens directly

314 interact with the ApoH protein, including S. aureus and S. pyogenes (Zhang et al, 1999).

315 Furthermore, binding to LPS causes ApoH to undergo a conformational change leading

316 to binding and clearance of bacteria during infection (Agar et al, 2011). This binding is

317 mediated largely by ionic and hydrophobic interactions (Hammel et al, 2001), instead of

318 the protein-specific interactions observed for some Gram-positive bacteria. This

319 difference in interaction mechanism may explain the slightly higher capture efficiency

320 observed for Gram-positive (67.7-92.0\%) versus Gram-negative (2.1-66.4\%) bacteria

321 (Figure 3).

322

323 The capture efficiency for bacteria observed in this study was comparable to similar

324 affinity-based separations, where, using different matrices, recovery has ranged from 33-

$325215 \%$ in broth to $13-50 \%$ in ground beef and milk (Stevens \& Jaykus, 2008).

326 Unfortunately, the recovery of E. coli O157:H7 using ApoH (2.1-5.0\%) was lower than

327 density gradient centrifugation (20-45\%) or crude filtration (10-95\%) (Stevens \& Jaykus,

328 2008), suggesting that the ApoH method sometimes underperforms relative to other

329 concentration approaches. A complementary plate-based capture assay showed that

330 ApoH bound to a variety of human norovirus VLPs. Taken together, the results 
331 demonstrate that $\mathrm{ApoH}$ has the potential to be a broadly reactive ligand for separating and

332 concentrating foodborne pathogens, with an affinity for a variety of human norvovirus

333 strains, in addition to select Gram-negative and Gram-positive of foodborne significance.

335 A single strategy to concentrate both enteric viruses and bacteria has not been previously

336 explored, making ApoH a unique capture ligand. A major advantage of joint capture is

337 the ability to use a single reagent for concentration and purification of multiple pathogen

338 targets. Of course, the specificity of ApoH-bacteria interactions is unknown, and it is

339 possible that the molecule shows broad binding affinity to a variety of microorganisms,

340 both pathogenic and non-pathogenic. Even if that were the case, ApoH would have

341 utility in food microbiology, although perhaps in a slightly different application. The

342 fact that the ApoH magnetic beads were able to capture bacteria amongst a background of

343 viruses, and vice versa, without significant loss of efficiency, bodes well for its use in

344 more complex sample matrices. However, the studies described here did not take into

345 account the potential impact of the sample matrix itself, which can be substantial.

346 Unfortunately, due to the proprietary nature of the ApoH product, we were unable to

347 obtain unconjugated beads for use as a negative control. In addition, a comprehensive

348 binding specificity study using related and unrelated bacteria and viruses was not

349 undertaken in our study. It therefore is unclear if the ligand-pathogen interaction is

350 specific or if a complex enough sample matrix could competitively saturate the beads.

351 Because the impact of the matrix is a black box, future studies should focus on using

352 ApoH to concentrate and separate both viral and bacterial pathogens from relevant food

353 and environmental samples. 
355 In summary, in this proof-of-concept study, ApoH was used for the concentration of key

356 foodborne bacteria and viruses prior to detection by nucleic acid amplification. For all

357 three viruses studied at all concentrations, $>10 \%$ capture efficiency $\left(<1 \log _{10} \operatorname{loss}\right.$ in RT-

358 qPCRU) was observed, even when viruses were co-captured in the presence of bacteria.

359 The same can be said for the bacterial pathogens tested, with the exception of $E$. coli

360 O157:H7 (approximately $1 \%$ capture efficiency, or $2 \log _{10} \operatorname{loss}$ ). The efficiency of the

361 capture steps did not vary as a consequence of input target concentration or in the

362 presence of an abundance of background microflora. The ApoH ligand performed well

363 for several human norovirus strains, as well as three different pathogenic bacteria,

364 making it relatively broadly reactive and amenable to concentration of multiple,

365 structurally different organisms. Further, the capture step appeared to work well in the

366 presence of background microflora. The next logical step is to evaluate the performance

367 of the methods in complex sample matrices, studies that are underway in our laboratory.

\section{Acknowledgements}

370 We thank E. Benedict for her help troubleshooting buffer conditions. This work was

371 supported in part by the Agriculture and Food Research Initiative Competitive Grant no.

372 2011-68003-30395 from the U.S. Department of Agriculture, National Institute of Food

373 Agriculture through the NoroCORE project. Additional support was provided by the U.S.

374 Air Force Institute of Technology Civilian Institute Program Scholarship. The views

375 expressed in this article are those of the authors and do not reflect the official policy or

376 position of the U.S. Air Force, Department of Defense, or the U.S. Government. 


\section{References}

378 Adlhoch C, Kaiser M, Hoehne M, Mas Marques A, Stefas I, Veas F, Ellerbrok H (2011)

379 Highly sensitive detection of the group A Rotavirus using Apolipoprotein H-coated

380 ELISA plates compared to quantitative real-time PCR. Virology journal 8: 63

381

382 Agar C, de Groot PG, Morgelin M, Monk SD, van Os G, Levels JH, de Laat B, Urbanus

383 RT, Herwald H, van der Poll T, Meijers JC (2011) beta(2)-glycoprotein I: a novel

384 component of innate immunity. Blood 117: 6939-6947

385

386 Alarcón B, Vicedo B, Aznar R (2006) PCR-based procedures for detection and

387 quantification of Staphylococcus aureus and their application in food. Journal of applied 388 microbiology 100: 352-364

390 Batz MB, Hoffmann S, Morris JG, Jr. (2012) Ranking the disease burden of 14 pathogens

391 in food sources in the United States using attribution data from outbreak investigations

392 and expert elicitation. J Food Prot 75: 1278-1291

393

394 Boulanger CA, Edelstein PH (1995) Precision and accuracy of recovery of Legionella 395 pneumophila from seeded tap water by filtration and centrifugation. Applied and

396 environmental microbiology 61: 1805-1809

398 Bouma B, de Groot PG, van den Elsen JM, Ravelli RB, Schouten A, Simmelink MJ,

399 Derksen RH, Kroon J, Gros P (1999) Adhesion mechanism of human beta(2)- 
400 glycoprotein I to phospholipids based on its crystal structure. The EMBO journal 18:

$401 \quad 5166-5174$

402

403 Centers for Disease C, Prevention (2013) Surveillance for foodborne disease outbreaks--

404 United States, 2009-2010. MMWR Morbidity and mortality weekly report 62: 41-47

405

406 Chen F, Hu YL, Li DQ, Chen HD, Zhang XL (2009) CS-SELEX Generates High-

407 Affinity ssDNA Aptamers as Molecular Probes for Hepatitis C Virus Envelope

408 Glycoprotein E2. PloS ONE 4

409

410 Cullison MA, Jaykus LA (2002) Magnetized carbonyl iron and insoluble zirconium

411 hydroxide mixture facilitates bacterial concentration and separation from nonfat dry milk.

412 J Food Prot 65: 1806-1810

413

414 Dwivedi HP, Jaykus LA (2011) Detection of pathogens in foods: the current state-of-the-

415 art and future directions. Crit Rev Microbiol 37: 40-63

416

417 Erlich HA, Gelfand D, Sninsky JJ (1991) Recent advances in the polymerase chain

418 reaction. Science 252: 1643-1651

419

420 Escudero-Abarca, BI, Suh, SH, Moore, MD, Dwivedi, HP., Jaykus, LA (2014) Selection,

421 characterization and application of nucleic acid aptamers for the capture and detection of

422 human norovirus strains. PLoS ONE 9 
424 Farkas T, Sestak K, Wei C, Jiang X (2008) Characterization of a rhesus monkey

425 calicivirus representing a new genus of Caliciviridae. Journal of virology 82: 5408-5416

426

427 Fluit AC, Torensma R, Visser MJ, Aarsman CJ, Poppelier MJ, Keller BH, Klapwijk P,

428 Verhoef J (1993a) Detection of Listeria monocytogenes in cheese with the magnetic

429 immuno-polymerase chain reaction assay. Applied and environmental microbiology 59:

$430 \quad 1289-1293$

431

432 Fluit AC, Widjojoatmodjo MN, Box AT, Torensma R, Verhoef J (1993b) Rapid detection

433 of salmonellae in poultry with the magnetic immuno-polymerase chain reaction assay.

434 Applied and environmental microbiology 59: 1342-1346

435

436 Gandhi M, Chikindas ML (2007) Listeria: A foodborne pathogen that knows how to

437 survive. International journal of food microbiology 113: 1-15

438

439 Godoy P, Stefas E, Ferrer P, Vollrath V, Vial P, Ferres M, Veas F, Lopez-Lastra M

440 (2008) ApoH-capture technology enhances Andes hantavirus detection allowing virus

441 concentration from plasma and urine samples of patients with acute hantavirus

442 cardiopulmonary syndrome. Infection Genetics and Evolution 8: S14-S15

443 
444 Hammel M, Schwarzenbacher R, Gries A, Kostner GM, Laggner P, Prassl R (2001)

445 Mechanism of the interaction of beta(2)-glycoprotein I with negatively charged

446 phospholipid membranes. Biochemistry 40: 14173-14181

447

448 Jothikumar N, Lowther JA, Henshilwood K, Lees DN, Hill VR, Vinje J (2005) Rapid and

449 sensitive detection of noroviruses by using TaqMan-based one-step reverse transcription-

450 PCR assays and application to naturally contaminated shellfish samples. Applied and

451 Environmental Microbiology 71: 1870-1875

452

453 Kadariya J, Smith TC, Thapaliya D (2014) Staphylococcus aureus and Staphylococcal

454 Food-Borne Disease: An Ongoing Challenge in Public Health. BioMed research

455 international 2014: 827965

456

457 Kageyama T, Kojima S, Shinohara M, Uchida K, Fukushi S, Hoshino FB, Takeda N,

458 Katayama K (2003) Broadly reactive and highly sensitive assay for Norwalk-like viruses

459 based on real-time quantitative reverse transcription-PCR. Journal of Clinical

$460 \quad$ Microbiology 41: 1548-1557

461

462 Kramer M, Obermajer N, Bogovic Matijasic B, Rogelj I, Kmetec V (2009) Quantification

463 of live and dead probiotic bacteria in lyophilised product by real-time PCR and by flow

464 cytometry. Applied microbiology and biotechnology 84: 1137-1147

465 
466 Kretzer JW, Lehmann R, Schmelcher M, Banz M, Kim KP, Korn C, Loessner MJ (2007)

467 Use of high-affinity cell wall-binding domains of bacteriophage endolysins for

468 immobilization and separation of bacterial cells. Applied and environmental microbiology

469 73: 1992-2000

470

471 Liebana S, Lermo A, Campoy S, Barbe J, Alegret S, Pividori MI (2009) Magneto

472 immunoseparation of pathogenic bacteria and electrochemical magneto genosensing of

473 the double-tagged amplicon. Analytical chemistry 81: 5812-5820

474

475 Malorny B, Paccassoni E, Fach P, Bunge C, Martin A, Helmuth R (2004) Diagnostic

476 real-time PCR for detection of Salmonella in food. Applied and environmental

477 microbiology 70: 7046-7052

478

479 Mehdi H, Kaplan MJ, Anlar FY, Yang X, Bayer R, Sutherland K, Peeples ME (1994)

480 Hepatitis B virus surface antigen binds to apolipoprotein H. Journal of virology 68: 2415-

$481 \quad 2424$

482

483 Nilsson M, Wasylik S, Morgelin M, Olin AI, Meijers JC, Derksen RH, de Groot PG,

484 Herwald H (2008) The antibacterial activity of peptides derived from human beta-2

485 glycoprotein I is inhibited by protein $\mathrm{H}$ and M1 protein from Streptococcus pyogenes.

486 Molecular microbiology 67: 482-492

487 
488 Pellicano R, Broutet N, Ponzetto A, Megraud F (1999) Helicobacter pylori: from the

489 stomach to the heart. European journal of gastroenterology \& hepatology 11: 1335-1337

490

491 Rangel JM, Sparling PH, Crowe C, Griffin PM, Swerdlow DL (2005) Epidemiology of

492 Escherichia coli O157:H7 outbreaks, United States, 1982-2002. Emerging infectious

493 diseases 11: 603-609

494

495 Rodríguez-Lázaro D, Hernández M, Scortti M, Esteve T, Vázquez-Boland JA, Pla M

496 (2004) Quantitative detection of Listeria monocytogenes and Listeria innocua by real-

497 time PCR: assessment of hly, iap, and lin02483 targets and AmpliFluor technology.

498 Applied and environmental microbiology 70: 1366-1377

499

500 Scallan E, Hoekstra RM, Angulo FJ, Tauxe RV, Widdowson MA, Roy SL, Jones JL,

501 Griffin PM (2011) Foodborne illness acquired in the United States--major pathogens.

502 Emerging infectious diseases 17: 7-15

503

504 Scharff RL (2012) Economic burden from health losses due to foodborne illness in the

505 United States. J Food Prot 75: 123-131

506

507 Sestak K, Feely S, Fey B, Dufour J, Hargitt E, Alvarez X, Pahar B, Gregoricus N, Vinje

508 J, Farkas T (2012) Experimental Inoculation of Juvenile Rhesus Macaques with Primate

509 Enteric Caliciviruses. Plos One 7

510 
511 Stefas E, Rucheton M, Graafland H, Moynier M, Sompeyrac C, Bahraoui EM, Veas F

512 (1997) Human plasmatic apolipoprotein H binds human immunodeficiency virus type 1

513 and type 2 proteins. AIDS research and human retroviruses 13: 97-104

514

515 Stefas I, Rucheton M, D'Angeac AD, Morel-Baccard C, Seigneurin JM, Zarski JP, Martin

516 M, Cerutti M, Bossy JP, Misse D, Graafland H, Veas F (2001) Hepatitis B virus Dane

517 particles bind to human plasma apolipoprotein H. Hepatology (Baltimore, Md) 33: 207-

$518 \quad 217$

519

520 Stevens KA, Jaykus LA (2004) Direct detection of bacterial pathogens in representative

521 dairy products using a combines bacterial concentration-PCR approach. Journal of

522 Applied Microbiology 97: 1115-1122

523

524 Stevens KA, Jaykus LA (2008) Bacterial separation and concentration from complex

525 sample matrices: a review. Crit Rev Microbiol 30: 7-24

526

527 Stojanovic M, Inic-Kanada A, Popovic Z, Zivkovic I, Dimitrijevic L (2004) Changes in

528 pools of autoantibodies and anti-bacterial antibodies in patients suffering from recurrent

529 infections of the urinary tract and undergoing bacterial immunization treatment.

530 Immunology letters 94: 123-133

531 
532 Takahashi H, Kimura B, Tanaka Y, Shinozaki J, Suda T, Fujii T (2009) Real-time PCR

533 and enrichment culture for sensitive detection and enumeration of Escherichia coli.

534 Journal of Microbiological Methods 79: 124-127

535

536 Teunis PFM, Moe CL, Liu P, Miller SE, Lindesmith L, Baric RS, Le Pendu J, Calderon

537 RL (2008) Norwalk virus: How infectious is it? Journal of Medical Virology 80: 1468-

$538 \quad 1476$

539

540 Tian P, Engelbrektson A, Mandrell R (2008) Two-log increase in sensitivity for detection

541 of norovirus in complex samples by concentration with porcine gastric mucin conjugated

542 to magnetic beads Applied and Environmental Microbiology 74:4271-4276.

543

544 Tian P, Bates AH, Jensen HM, Mandrell RE (2006). Norovirus binds to blood group A-

545 like antigens in oyster gastrointestinal cells. Letters in Applied Microbiology, 43: 645-

$546 \quad 651$

547

548 Tian P, Yang D, Jiang X, Zhong W, Cannon JL, Burkhardt W, Woods JW, Hartman G,

549 Lindesmith L, Baric RS, Mandrell R (2010) Specificity and kinetics of norovirus binding

550 to magnetic bead-conjugated histo-blood group antigens. Journal of Applied

551 Microbiology 109: 1753-1762

552

553 Tung G, Macinga D, Arbogast J, Jaykus LA (2013) Efficacy of commonly used

554 disinfectants for inactivation of human noroviruses and their surrogates. Journal of Food 
555 Protection 76: $1210-1217$

556

557 Wang RH, Zhao JJ, Jiang TS, Kwon YM, Lu HG, Jiao PR, Liao M, Li YB (2013)

558 Selection and characterization of DNA aptamers for use in detection of avian influenza

559 virus H5N1. Journal of Virological Methods 189: 362-369

560

561 Zhang L, Jacobsson K, Strom K, Lindberg M, Frykberg L (1999) Staphylococcus aureus

562 expresses a cell surface protein that binds both $\mathrm{IgG}$ and beta2-glycoprotein I.

563 Microbiology 145 ( Pt 1): 177-183 
564 Table 1. Primers and probes used for RT-qPCR detection of viruses and qPCR detection of bacteria.

\begin{tabular}{|c|c|c|}
\hline \multirow{5}{*}{$\begin{array}{l}\text { Pathogen } \\
\text { GI.1 Norwalk }\end{array}$} & Primers and Probes & Reference \\
\hline & COG1F 5'-CGYTGGATGCGNTTYCATGA-3' & \multirow[t]{4}{*}{ Kageyama et al (2003) } \\
\hline & COG1R 5'-CTTAGACGCCATCATCATTYAC-3' & \\
\hline & RING1a 5' -6-FAM-AGATYGCGATCYCCTGTCCA-BHQ-3' & \\
\hline & RING1b 5'-6-FAM-AGATCGCGGTCTCCTGTCCA-BHQ-3' & \\
\hline GII.4 New & JJV2F 5'-CAAGAGTCAATGTTTAGGTGGATGAG-3' & \multirow{3}{*}{$\begin{array}{l}\text { Jothikumar et al } \\
(2005) \text {; Kageyama et al } \\
(2003)\end{array}$} \\
\hline Orleans & COG2R 5'-TCGACGCCATCTTCATTCACA-3' & \\
\hline & RING2P 5'-6-FAM-TGGGAGGGCGATCGCAATCT-BHQ-3' & \\
\hline \multirow[t]{3}{*}{ Tulane Virus } & TV2F 5’-GAGATTGGTGTCAAAACACTCTTTG-3’' & \multirow[t]{3}{*}{ Sestak et al (2012) } \\
\hline & TV2R 5'-ATCCAGTGGCACACACAATTT-3' & \\
\hline & TVP 5'-6-FAM-AGTTGATTGACCTGCTGTGTCA-BHQ-3' & \\
\hline \multirow[t]{3}{*}{ E. coli } & ECN1254F 5'-GCAAGGTGCACGGGAATATT-3’' & \multirow[t]{3}{*}{ (Takahashi et al, 2009) } \\
\hline & ECN1328R 5'-CAGGTGATCGGACGCGT-3' & \\
\hline & ECL1277P 5'-6-FAM-CGCCACTGGCGGAAGCAACG-BHQ-3' & \\
\hline \multirow[t]{3}{*}{ L. monocytogenes } & hlyQF 5'-CATGGCACCACCAGCATCT-3' & \multirow{3}{*}{$\begin{array}{l}\text { (Rodríguez-Lázaro et } \\
\text { al, 2004) }\end{array}$} \\
\hline & hlyQR 5'-ATCCGCGTGTTTCTTTTCGA-3' & \\
\hline & hlyQP 5'-6-FAM-CGCCTGCAAGTCCTAAGACGCCA-BHQ-3' & \\
\hline \multirow[t]{3}{*}{ S. enterica } & ttr-6 5'-CTCACCAGGAGATTACAACATGG-3' & \multirow[t]{3}{*}{ (Malorny et al, 2004) } \\
\hline & ttr-4 5'-AGCTCAGACCAAAAGTGACCATC-3' & \\
\hline & ttr-5 5'-6-FAM-CACCGACGGCGAGACCGACTTT-BHQ-3' & \\
\hline \multirow[t]{3}{*}{ S. aureus } & nucF372 5'-TGTAGTTTCAAGTCTAAGTAGCTCAGCAA-3' & \multirow[t]{3}{*}{ (Alarcón et al, 2006) } \\
\hline & nucR465 5’-TGCACTATATACTGTTGGATCTTCAGAA-3’' & \\
\hline & nuc 5'-6-FAM-TGCATCACAAACAGATAACGGCGTAA-BHQ-3' & \\
\hline
\end{tabular}

